\section{Percutaneous closure of iatrogenic arteriovenous fistula after pacemaker implantation}

A 76-year-old man presented with swelling of the left upper limb that started 1 year after pacemaker implantation. During the procedure, a single-pass VDD lead was introduced through an axillary vein puncture and was positioned in the right ventricular apex.

Pitting oedema of the left upper limb was seen, with reddishbrown skin pigmentation, scaling and thickening (figure 1A). Subclavian angiography showed a connection between the left axillary artery and vein (figure 1B). A self-expanding covered stent was deployed across the fistula. Postprocedure angiogram showed minimal residual shunt (figure 2A, online supplementary video 1). At 4 months, there was significant reduction in the oedema of the left upper limb (figure 2B).

Iatrogenic arteriovenous fistula (AVF) occurs mostly in the lower limb after femoral arterial or venous puncture for percutaneous procedures. AVF following axillary or subclavian vein puncture for pacemaker implantation has rarely been reported. ${ }^{1}$ The fistula can be closed surgically or by injection of sclerotherapy agents, alcohol or cyanoacrylate gel. However, today endovascular treatment with covered stent graft is the treatment of choice for AVF due to its high success rate and low morbidity. ${ }^{2}$

Praveen Kumar Gupta, Santhosh Satheesh, Raja J Selvaraj
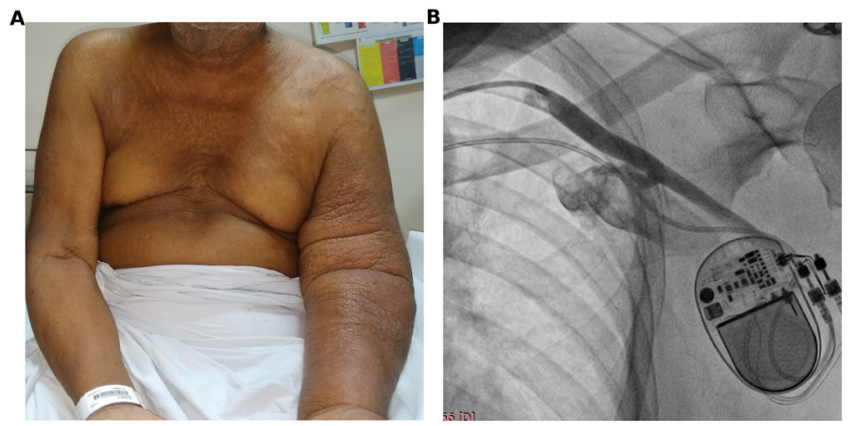

Figure 1 Presentation. (A) Massive oedema of the left upper limb is seen. (B) Subclavian angiography shows the fistulous connection between the left axillary artery and the left axillary vein.
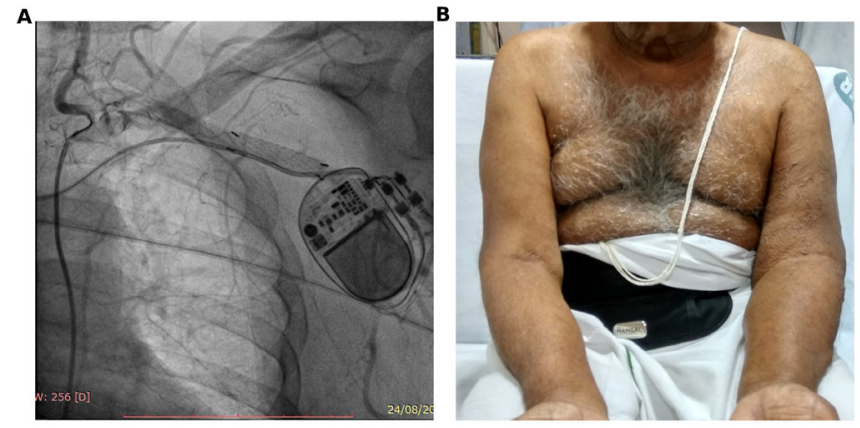

Figure 2 Follow-up. (A) Angiogram after the procedure with minimal residual shunt. (B) 4-month follow-up showing significant reduction in the left upper limb oedema.

Department of Cardiology, Jawaharlal Institute of Postgraduate Medical Education and Research (JIPMER), Pondicherry, India

Correspondence to Dr Raja I Selvaraj, Department of Cardiology, JIPMER, Pondicherry605006, India; rajajs@gmail.com

Contributors All authors were involved in the clinical care of the patient and preparation of the manuscript.

Funding The authors have not declared a specific grant for this research from any funding agency in the public, commercial or not-for-profit sectors.

Competing interests None declared.

Patient consent Obtained.

Provenance and peer review Not commissioned; internally peer reviewed.

(c) Author(s) (or their employer(s)) 2018. No commercial re-use. See rights and permissions. Published by BMJ.

- Additional material is published online only. To view please visit the journal online (http://dx.doi.org/10.1136/heartasia-2018-011072).

\section{Check for updates}

To cite Gupta PK, Satheesh S, Selvaraj RJ. Heart Asia 2018;10:e011072.

Heart Asia 2018;10:e011072. doi:10.1136/heartasia-2018-011072

\section{REFERENCES}

1. Lukies MW, Osuga K, Nakazawa T, et al. Endovascular management of an acquired subclavian arteriovenous fistula secondary to chronic venous occlusion after pacemaker insertion. Interventional Radiology 2017:2:33-7.

2. Parodi JC, Schönholz C, Ferreira LM, et al. Endovascular stent-graft treatment of traumatic arterial lesions. Ann Vasc Surg 1999;13:121-9. 